\title{
Comparação entre a eficácia da cimetidina e do sulfato de zinco no tratamento de verrugas múltiplas e recalcitrantes
}

\section{Efficacy comparison between cimetidine and zinc sulphate in the treatment}

\author{
of multiple and recalcitrant warts
}

\author{
Mariane Stefani ${ }^{1}$ \\ Elisa Fontenelle ${ }^{3}$
}

\author{
Giuliana Bottino $^{2}$ \\ David Rubem Azulay ${ }^{4}$
}

\begin{abstract}
Resumo: FUNDAMENTOS: Verrugas são proliferações epiteliais na pele e mucosas causadas por diversos tipos de HPV. Elas podem involuir espontaneamente ou aumentar em número e tamanho de acordo com estado imunitário do paciente. A cimetidina e o sulfato de zinco têm importante efeito no sistema imune, sendo usados como imunomoduladores no tratamento de diversas doenças.

Овјетіvо: Comparar a eficácia terapêutica de cimetidina e sulfato de zinco no tratamento de verrugas cutâneas de difícil tratamento.
\end{abstract}

MÉTODos: Estudo prospectivo duplo-cego randomizado. Dezoito pacientes com verrugas múltiplas foram divididos em dois grupos, um recebeu cimetidina $35 \mathrm{mg} / \mathrm{kg} / \mathrm{dia}$ (máximo $1.200 \mathrm{mg} / \mathrm{dia}$ ), e o outro, sulfato de zinco $10 \mathrm{mg} / \mathrm{kg} / \mathrm{dia}$ (máximo de $600 \mathrm{mg} / \mathrm{dia}$ ) por três meses.

RESultados: Dos 18 pacientes do estudo, nove receberam cimetidina, e nove, sulfato de zinco; apenas um do grupo do sulfato de zinco não completou o tratamento devido a náuseas e vômitos. Cura foi obtida em cinco pacientes tratados com sulfato de zinco, e apenas um não obteve alteração das lesões. Do grupo da cimetidina cinco não apresentaram modificação, e quatro apresentaram diminuição inferior a 30\% das lesões iniciais.

Conclusões: Sulfato de zinco na dose de $10 \mathrm{mg} / \mathrm{kg} /$ dia parece ser mais efetivo que cimetidina para o tratamento de crianças e adultos com verrugas múltiplas e de difícil manejo. A pequena casuística deste trabalho não permite, entretanto, conclusão categórica.

Palavras-chave: Cimetidina; Papillomaviridae; Sulfato de zinco; Verrugas; Verrugas/terapia

\begin{abstract}
Background: Warts are epithelial proliferations on the skin and mucous membrane caused by various types of HPV. They can decrease spontaneously or increase in number and size according to patient's immune status. Cimetidine and zinc sulphate have important effects on the immune system and are used as immunomodulators in the treatment of various diseases.

Objective: To compare the efficacy of cimetidine and zinc sulphate in the treatment of multiple and recalcitrant warts. Methods: A random double-blind prospective study. Eighteen patients with multiple warts were divided into two groups: one took $35 \mathrm{mg} / \mathrm{Kg} /$ day of cimetidine (maximum $1200 \mathrm{mg} /$ day) and the other $10 \mathrm{mg} / \mathrm{Kg} / \mathrm{day}$ of zinc sulphate (maximum $600 \mathrm{mg} /$ day) for three months.

Results: Among the 18 patients who participated in the study, nine took cimetidine and nine zinc sulphate. Just one patient in the zinc sulphate group did not complete treatment due to nausea and vomiting. Five patients who were treated with zinc sulphate were cured and only one did not show modifications in lesions. Among the group who was treated with cimetidine, five did not show modifications in lesions and four showed decrease from baseline below $30 \%$.

Conclusions: $10 \mathrm{mg} / \mathrm{Kg} /$ day zinc sulphate dose seems to be more effective than cimetidine for the treatment of children and adults with multiple and difficult-to-handle warts. However, the small number of patients did not enable any definitive conclusion.

Keywords: Cimetidine; Papillomaviridae; Zinc sulphate; Warts; Warts/therapy
\end{abstract}

Recebido em 15.06.2007.

Aprovado pelo Conselho Consultivo e aceito para publicação em 08.12.08

* Trabalho realizado no Instituto de Dermatologia Professor Rubem David Azulay da Santa Casa de Misericórdia do Rio de Janeiro - Rio de Janeiro (RJ), Brasil. Conflito de interesse: Nenhum / Conflict of interest: None

Suporte financeiro: Nenhum / Financial funding: None

Especialista em dermatologia pela Sociedade Brasileira de Dermatologia e especialista em pediatria - Caxias do Sul (RS), Brasil.

Especialista em dermatologia pela Sociedade Brasileira de Dermatologia e especialista em clínica médica - Rio de Janeiro (RJ), Brasil.

Responsável pelo Ambulatório de Dermatologia Pediátrica do Instituto de Dermatologia Professor Rubem David Azulay da Santa Casa de Misericórdia do Rio de Janeiro, dermatologista do Hospital Municipal Jesus - Rio de Janeiro (RJ), Brasil.

Chefe de Serviço do Instituto de Dermatologia Professor Rubem David Azulay da Santa Casa de Misericórdia do Rio de Janeiro. Professor titular da Pontifícia Universidade Católica do Rio de Janeiro (PUC-Rio) e assistente da Fundação Técnico-Educacional Souza Marques (FTESM) e Universidade Federal do Rio de Janeiro (UFRJ) - Rio de Janeiro (RJ), Brasil.

(C)2009 by Anais Brasileiros de Dermatologia 


\section{INTRODUÇÃO}

Verrugas são proliferações epiteliais na pele e mucosas causadas por diversos tipos de papilomavírus humano (HPV). Ocorrem em qualquer idade, sendo mais comum em crianças e adolescentes. A lesão é autoinoculável, e o tempo de incubação, variável, de poucas semanas a mais de um ano. ${ }^{1}$

Elas podem involuir espontaneamente ou aumentar em número e tamanho de acordo com o estado imunitário do paciente. A imunidade celular é muito importante, e verrugas são particularmente exuberantes em pacientes com doença de Hodgkin, Aids e também em pacientes sob a ação de agentes imunossupressores. Quarenta e cinco por cento dos pacientes imunossuprimidos devido a transplante renal têm verrugas principalmente vulgar e plantar antes de cinco anos após o transplante, percentual que, após esse período, salta para mais de $70 \%$. Imunidade humoral parece ser menos importante, pois pacientes com mieloma múltiplo não são particularmente propensos a elas. ${ }^{2}$

As verrugas podem ser divididas em vulgares (as mais comuns), filiformes, plantares tipo mirmécia ou mosaico, periungueais, planas, genitais e orais. ${ }^{13-5}$

Há diversos tratamentos para as verrugas, como eletrocoagulação, nitrogênio líquido, ácido nítrico fumegante, colódio flexível e muitos outros. Em alguns casos, devido ao grande número e à dor, esses tratamentos são impraticáveis. ${ }^{1,3 \cdot 5}$

O uso de sulfato de zinco por via oral está bem estabelecido para o tratamento da acrodermatite enteropática. Em outras condições, a deficiência de zinco tem sido reconhecida, podendo ter várias causas determinantes, como alcoolismo, alterações gastrointestinais, insuficiência pancreática, cirrose, síndrome de má absorção, queimaduras, neoplasias, infecções, doenças renais e nutrição parenteral. Alguns trabalhos referem eficácia terapêutica com sulfato de zinco na alopecia areata, prurido urêmico, leishmaniose cutânea, perifoliculite capitis abscendens et sufodiens ${ }^{4,6}$ e acne inflamatória. ${ }^{7}$ Outro trabalho evidencia a eficácia do sulfato de zinco no tratamento de verrugas recalcitrantes. A deficiência de zinco determina ainda hipoplasia tímica com repercussão na maturação das células $\mathrm{T}$, resultando em deficiências imunológicas que favorecem infecções associadas. ${ }^{4,6}$

A cimetidina é um antagonista de receptor $\mathrm{H} 2$ e tem efeito imunomodulador, sendo usada em crianças para tratar verrugas $;{ }^{8-10} \mathrm{em}$ adultos, entretanto, o uso de cimetidina no tratamento de verrugas tem resultados conflitantes. ${ }^{1,5,11,12}$

Em vista disso, torna-se interessante estabelecer a eficácia terapêutica da cimetidina e do sulfato de zinco nos pacientes com verrugas recalcitrantes e múltiplas.

\section{MATERIAL E MÉTODOS}

Este estudo prospectivo duplo-cego randomizado, realizado no período de abril a dezembro de 2006, no Instituto de Dermatologia Professor Rubem David Azulay, consistiu no tratamento de pacientes com verrugas cutâneas múltiplas e/ou recalcitrantes. Dezoito pacientes foram divididos em dois grupos aleatoriamente conforme a demanda: um grupo recebeu cimetidina $35 \mathrm{mg} / \mathrm{kg} / \mathrm{dia}$ (máximo $1.200 \mathrm{mg} / \mathrm{dia}$ ), e o outro, sulfato de zinco $10 \mathrm{mg} / \mathrm{kg} /$ dia (máximo de $600 \mathrm{mg} / \mathrm{dia}$ ) por três meses.

Os pacientes foram selecionados usando os seguintes critérios: presença de 10 ou mais verrugas cutâneas ou verrugas recalcitrantes, isto é, pacientes que já haviam sido submetidos a dois ou mais tratamentos por métodos destrutivos sem resolução do quadro clínico, tendo o último tratamento terminado pelo menos dois meses antes de iniciar a pesquisa; ausência de doenças crônicas; comprometimento com a não-utilização de outras medicações durante o tratamento e assinatura de termo de consentimento para participar do trabalho.

Os critérios de exclusão foram os seguintes: presença de imunodeficiências; gravidez; utilização de drogas imunossupressoras e medicamentos que inibam a atividade do citocromo $\mathbf{P} 450$.

O estudo teve a aprovação do comitê de ética do Hospital Santa Casa de Misericórdia do Rio de Janeiro. Os pacientes selecionados foram encaminhados para duas médicas que ficaram responsáveis pelo preenchimento das fichas e acompanhamento mensal sem saber qual dos dois medicamentos o paciente estava recebendo. Uma terceira médica ficou responsável pela prescrição das medicações, dividindo aleatoriamente os pacientes em dois grupos, cada um com nove pacientes. Os pacientes desconheciam a medicação recebida.

As revisões foram mensais, observando o número de verrugas e os efeitos colaterais das medicações. Os pacientes se submeteram ao tratamento por três meses e foram acompanhados mensalmente por mais dois meses após o término do tratamento. As medicações foram fornecidas ao paciente gratuitamente, sendo manipuladas todas na mesma farmácia.

A análise estatística foi realizada pelo teste não paramétrico de Mann-Whitney para comparação da idade e duração da doença entre os dois grupos do estudo; para comparação da proporção de resposta clínica foi aplicado o teste exato de Fisher. Foi utilizado teste não paramétrico, pois a idade e a duração da doença não apresentaram distribuição gaussiana devido à dispersão dos dados e/ou a falta de simetria da distribuição. O critério de determinação de significância adotado foi o nível de 5\%. A análise estatística foi processada pelo software SAS 6.04 (SAS Institute, Inc., Cary, North Carolina).

\section{RESULTADOS}

Dos 18 pacientes do estudo, nove receberam cimetidina, e nove, sulfato de zinco, sendo oito do sexo masculino e um do sexo feminino em cada grupo. $\mathrm{O}$ número de verrugas dos pacientes variou de 11 a 120 . A tabela 1 mostra a análise estatística da idade e da dura- 
ção da doença segundo a medicação. Observou-se que não existia diferença significativa na idade $(p=0,84)$ e na duração da doença $(p=0,73)$ entre os dois grupos do estudo.

A tabela 2 mostra a freqüência e o percentual da resposta clínica segundo a medicação. Observou-se que existia diferença significativa na proporção de resposta clínica entre os dois grupos do estudo $(p=0,024)$. O grupo tratado com sulfato de zinco apresentou proporção de resposta completa significativamente superior à do grupo tratado com cimetidina. Por outro lado, o grupo tratado com cimetidina apresentou proporção de ausência de resposta significativamente superior à do grupo tratado com sulfato de zinco.

As características dos cinco pacientes que obtiveram resolução completa das verrugas com sulfato de zinco estão demonstradas no quadro 1 . As figuras 1 e 2 mostram os pacientes um e dois desses cinco antes de iniciar o tratamento e após o término do tratamento.

Apenas um paciente tratado com sulfato de zinco não obteve alteração das lesões, um apresentou melhora de $36 \%$, e outro de $85,72 \%$.

Os efeitos colaterais relatados pelos pacientes que receberam cimetidina foram náuseas, epigastralgia, prurido difuso e dor nas lesões, sendo que quatro pacientes não apresentaram efeitos colaterais. Quanto aos pacientes que receberam sulfato de zinco, o sintoma mais freqüente em cinco deles consistiu em náuseas; dois queixaram-se de vômitos, e um de diarréia, tendo quatro pacientes também não apresentado nenhum sintoma. Apenas uma paciente de seis anos abandonou o tratamento devido a náuseas e vômitos. Em ambos os grupos os efeitos foram atenuados dividindo a dose total em três doses diárias e ingerindo a medicação às refeições.

\section{DISCUSSÃO}

As verrugas são causadas por DNA-vírus de dupla hélice que pertencem à família papovaviridae e ao gênero papilomavírus. ${ }^{3}$ A prevalência das verrugas na população geral é desconhecida, estimando-se a incidência de 3-20\% em crianças em idade escolar. ${ }^{1} \mathrm{O}$ pico de incidência ocorre entre os 12 e 16 anos, sendo $70 \%$ delas vulga- res, $24 \%$ plantares, $3,5 \%$ planas, $2 \%$ filiformes e $0,5 \%$ anogenitais. Neste estudo a idade dos pacientes variou de cinco a 63 anos. Os pacientes não foram pareados segundo as localizações das verrugas, pois vários apresentavam mais de um tipo de verruga e mais de uma área do corpo afetada. Os tipos de HPV mais freqüentes na verruga plana são 3 e 10; na verruga vulgar, palmar e plantar, HPV 1, 2 e $4 .{ }^{1,3}$

A transmissão de HPV ocorre através de pequenas soluções de continuidade na pele, explicando sua localização em área de trauma. ${ }^{1,3,5}$ A cura espontânea das verrugas pode ocorrer, mas demanda longo tempo, geralmente alguns anos. Em crianças a regressão espontânea das verrugas pode chegar a $60 \% \mathrm{em}$ dois anos de acompanhamento, mas algumas podem não mostrar essa cura em longos períodos de seguimento e ainda apresentar novas lesões nesse período. ${ }^{1,3-5}$ A duração das lesões dos pacientes deste estudo foi de quatro meses a cinco anos. Seria interessante num próximo estudo fazer pareamento por faixa etária e acrescentar um grupo controle placebo para tentar observar essa situação de regressão espontânea em crianças.

Numerosas pesquisas em humanos e animais têm demonstrado disfunção imune celular e humoral em todos os níveis de privação de zinco, se por grandes períodos de tempo. ${ }^{13,14}$ A deficiência marginal de zinco em recém-nascidos e crianças tem sido mostrada como causadora de falha no desenvolvimento, a partir de vários parâmetros antropométricos. ${ }^{15}$

$\mathrm{Na}$ acrodermatite enteropática a atrofia tímica é uma conseqüência; como resultado, os timócitos e as funções imunocelulares, especialmente uma grande série de funções das células $\mathrm{T}$, ficam debilitados. Neutrófilos, monócitos do sangue periférico, macrófagos de tecidos e mastócitos são conhecidos por exigir excelentes concentrações de zinco para seu funcionamento normal. ${ }^{15}$

A deficiência marginal de zinco pode ser silenciosa na patogênese de diversas doenças sistêmicas e da pele; função linfocítica anormal, suscetibilidade aumentada para infecção, cicatrização demorada e destruição de radicais livres são prejudicadas. ${ }^{15}$

Al-Gurairi e col. utilizaram para o tratamento de

TABELA 1: Análise estatística da idade dos pacientes e da duração das verrugas nos grupos que utilizaram sulfato de zinco e cimetidina

\begin{tabular}{|c|c|c|c|c|c|c|c|c|}
\hline Variável & Medicação & $\mathbf{N}$ & Média & DP & Mediana & Mínimo & Máximo & P valor ${ }^{a}$ \\
\hline Idade & Sulfato de zinco & 8 & 27 & 21,8 & 18 & 7 & 63 & 0,84 \\
\hline (anos) & Cimetidina & 9 & 22,1 & 14,4 & 21 & 5 & 50 & \\
\hline Duração da doença & Sulfato de zinco & 8 & 22,5 & 17,5 & 12 & 12 & 60 & 0,73 \\
\hline (meses) & Cimetidina & 9 & 21,8 & 17,4 & 18 & 4 & 60 & \\
\hline
\end{tabular}

DP: Desvio Padrão

Teste de Mann-Whitney 
TABela 2: Resposta clínica obtida através do tratamento de verrugas com cimetidina e sulfato de zinco

\begin{tabular}{|c|c|c|c|}
\hline \multicolumn{4}{|c|}{ Medicação } \\
\hline Cimetidina & Sulfato de zinco & Total & \\
\hline Resposta parcial & $4(44,4 \%)$ & $2(25 \%)$ & 6 \\
\hline Sem resposta & $5(55,6 \%)$ & $1(12,5 \%)$ & 6 \\
\hline
\end{tabular}

verrugas recalcitrantes $10 \mathrm{mg} / \mathrm{kg} / \mathrm{dia}$ de sulfato de zinco (máximo 600mg/dia). Dos 40 pacientes que receberam sulfato de zinco apenas 23 completaram o tratamento, e, destes, 20 obtiveram cura das lesões em dois meses de tratamento. Os efeitos colaterais relatados foram prurido, náusea, vômito e dor epigástrica passageiros. ${ }^{6}$

O presente estudo mostra cura em cinco $(62,5 \%)$ dos oito pacientes que terminaram o tratamento. $\mathrm{E}$ os efeitos colaterais mais relatados foram náusea por cinco (41,66\%) pacientes, vômito por dois $(16,66 \%)$ e diarréia por um $(8,33 \%)$. Esses efeitos podem ser reduzidos dividindo a dose total em três doses diárias ingeridas às refeições. Esse recurso foi utilizado, com alívio dos sintomas, mas uma paciente de seis anos não tolerou a medicação devido a náuseas e vômitos, abandonando o tratamento.

A dose de $2,5 \mathrm{mg} / \mathrm{kg} /$ dia (máximo $150 \mathrm{mg} / \mathrm{dia}$ ) de zinco elementar que foi utilizada neste estudo é segura. Doses farmacológicas de quatro a $12 \mathrm{mg} / \mathrm{kg} / \mathrm{dia}$ de zinco elementar podem induzir gastroenterite, sangramento gastrointestinal, microcitose, neutropenia relativa e hipoceruloplasminemia. O uso prolongado pode induzir deficiência de cobre e anemia, a qual responde à retirada do zinco. ${ }^{6}$
O zinco pode ser administrado na forma de acetato, gluconato ou sulfato, mas o último parece ser mais bem tolerado. Uma cápsula de $100 \mathrm{mg}$ de sulfato de zinco contém $22,5 \mathrm{mg}$ de zinco elementar.

Proteína animal e frutos do mar são ricos em zinco. ${ }^{16} \mathrm{O}$ estudo de sua biodisponibilidade é importante, pois há certas substâncias que modificam sua absorção. Os fitatos estão presentes na maioria dos grãos de cereais e vegetais, sendo potentes quelantes de zinco. ${ }^{7,15,16}$ Outros quelantes do zinco são as tetraciclinas, penicilinas, os corticosteróides, altas doses de ferro e cálcio, álcool, taninos e contraceptivos orais. ${ }^{7}$ Suplementações de zinco reduzem a absorção de quinolonas, ferro, penicilamina e tetraciclinas.

Os níveis plasmáticos normais de zinco variam de $70 \mathrm{a} 110 \mu \mathrm{g} / \mathrm{dl}$. A atividade da fosfatase alcalina no soro é indicador moderadamente sensível da condição do zinco, embora não seja particularmente marcador precoce da insuficiência. Sua atividade permanece próxima do normal até que exista deficiência excessiva e prolongada.

A coleta de amostras e a técnica laboratorial são importantes, pois a contaminação com o zinco ambiental ou em tubos de ensaio é ameaça constante. O tempo decorrido entre a coleta do sangue e a separação de soro

QUADRo 1: Características dos pacientes que obtiveram resolução completa das verrugas com sulfato de zinco

\begin{tabular}{|c|c|c|c|c|c|c|c|}
\hline Paciente & Sexo & Idade (anos) & $\begin{array}{l}\text { Número de } \\
\text { verrugas }\end{array}$ & $\begin{array}{l}\text { Duração da } \\
\text { doença }\end{array}$ & $\begin{array}{l}\text { Tipo de } \\
\text { verruga }\end{array}$ & $\begin{array}{l}\text { Local das } \\
\text { lesões }\end{array}$ & Cura \\
\hline 1 & M & 20 & 120 & 1 ano & $\begin{array}{l}\text { Vulgar } \\
\text { Periungueal } \\
\text { Filiforme }\end{array}$ & $\begin{array}{l}\text { Mãos } \\
\text { Pé } \\
\text { Perna }\end{array}$ & $\begin{array}{l}2^{\circ} \text { mês } \\
\text { após } \\
\text { término do } \\
\text { tratamento }\end{array}$ \\
\hline 2 & M & 23 & 23 & 2 anos & $\begin{array}{l}\text { Vulgar } \\
\text { Periungueal } \\
\text { Plantar }\end{array}$ & $\begin{array}{l}\text { Mãos } \\
\text { Pernas } \\
\text { Pés }\end{array}$ & $\begin{array}{l}3^{-} \text {mês de } \\
\text { tratamento }\end{array}$ \\
\hline 3 & M & 7 & 15 & $<1$ ano & $\begin{array}{l}\text { Vulgar } \\
\text { Periungueal }\end{array}$ & $\begin{array}{l}\text { Mãos } \\
\text { Pernas }\end{array}$ & $\begin{array}{l}3^{\circ} \text { mês de } \\
\text { tratamento }\end{array}$ \\
\hline 4 & $\mathbf{M}$ & 16 & 11 & 1 ano & $\begin{array}{l}\text { Vulgar } \\
\text { Periungueal }\end{array}$ & Mãos & $\begin{array}{l}1^{\circ} \text { mês de } \\
\text { tratamento }\end{array}$ \\
\hline 5 & M & 12 & 49 & $<1$ ano & $\begin{array}{l}\text { Vulgar } \\
\text { Filiforme } \\
\text { Plana }\end{array}$ & $\begin{array}{l}\text { Mãos } \\
\text { Face }\end{array}$ & $\begin{array}{l}2^{\circ} \text { mês de } \\
\text { tratamento }\end{array}$ \\
\hline
\end{tabular}



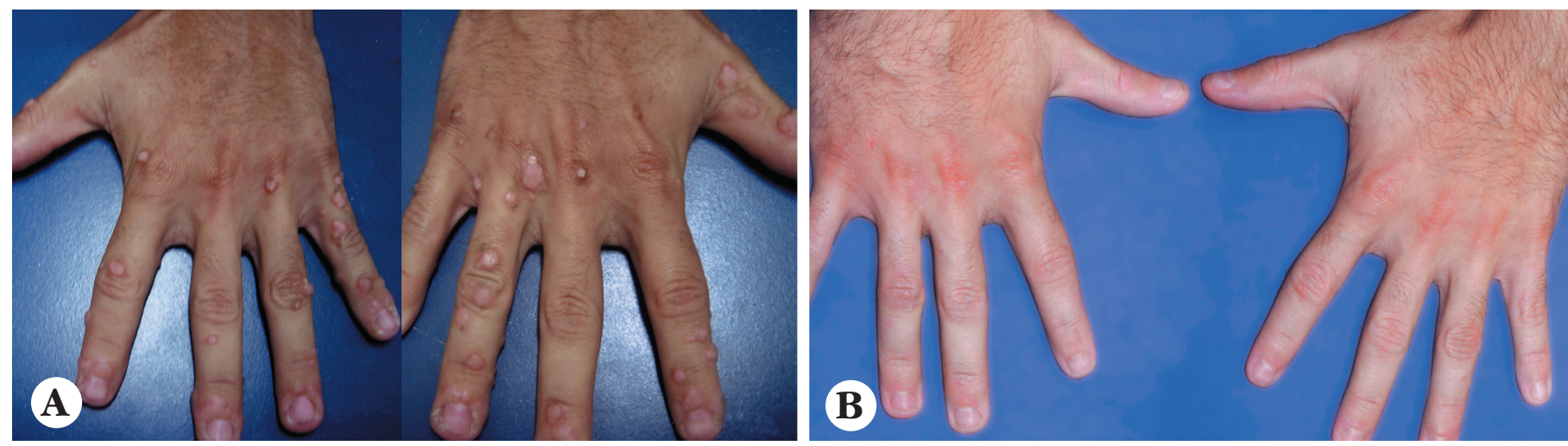

Figura 1: A Paciente 1, com verrugas vulgares e periungueais antes de iniciar tratamento com sulfato de zinco; B; dois meses após término do tratamento, com cura das lesões

e plasma também afeta a concentração de zinco, com aumento na concentração do plasma de até $6 \%$ nas primeiras duas horas se não for separado. É recomendável usar tubos a vácuo sem zinco e agulhas de aço inoxidável, evitar contato com tampas de borracha e hemólise, separar o plasma ou soro das células em 45 minutos e usar anticoagulantes sem zinco. Há um ritmo diurno na concentração de zinco plasmático, e o jejum matutino é recomendável para valores mais exatos. ${ }^{15}$ Não foi utilizada aqui a dosagem sérica do zinco devido a todas essas características peculiares e difíceis na obtenção da dosagem acurada do zinco, e ao custo elevado do exame, pois os pacientes envolvidos neste estudo são de baixa renda.

$\mathrm{Na}$ dermatologia a cimetidina, que é um antagonista de receptor $\mathrm{H} 2$, tem sido usada no tratamento de urticária, mastocitose, várias dermatoses eosinofílicas, verrugas, condiloma acuminado extenso, molusco contagioso $^{17}$ e epidermodisplasia verruciforme. ${ }^{18}$

É baixa a incidência de reações adversas - que são geralmente mínimas -, sendo inferior a 3\%. Neste estudo os efeitos colaterais mais freqüentes com o uso da cimetidina foram náusea, epigastralgia e prurido difuso em $18,18 \%$ dos pacientes, mas que também foram atenuados dividindo a dose total e ingerindo com alimentação. Esses agentes são bem tolerados em doses muito acima das necessárias para promover inibição substancial da secreção de ácido gástrico. Conseqüentemente, a despeito de suas curtas meias-vidas plasmáticas, os antagonistas de receptor $\mathrm{H} 2$ podem ser administrados em quantidades relativamente grandes uma ou duas vezes ao dia para promover terapia efetiva. ${ }^{10}$

A cimetidina tem-se mostrado imunomodulador, provavelmente bloqueando os receptores $\mathrm{H} 2$ das células T supressoras, aumentando a imunidade celular. A administração de cimetidina aumenta a proliferação de linfócitos, inibe a função das células $\mathrm{T}$ supressoras e aumenta a reatividade aos testes cutâneos. Ela tem sido usada com sucesso para estimular o sistema imune de pacientes com imunodeficiências mediadas por células T, como imunodeficiência comum variável, candidíase mucocutânea, ${ }^{8,17,19}$ hiperimunoglobulinemia E e herpes-zóster crô- nico em paciente imunocomprometido. ${ }^{8}$

Altas doses de cimetidina $30-40 \mathrm{mg} / \mathrm{kg} / \mathrm{dia}$ tem sido relatado como efetivo no tratamento de verrugas recalcitrantes em adultos ${ }^{12,20}$ e crianças, ${ }^{8,19,20}$ mas outros estudos não têm observado melhores resultados da cimetidina em relação ao placebo. ${ }^{11,21-23}$

Neste trabalho o uso da cimetidina para verrugas múltiplas não curou nenhum paciente; três apresentaram diminuição do tamanho, e três diminuição do número das lesões, mas diminuição inferior a 30\% das lesões iniciais, com resultados pouco expressivos, não justificando seu uso.
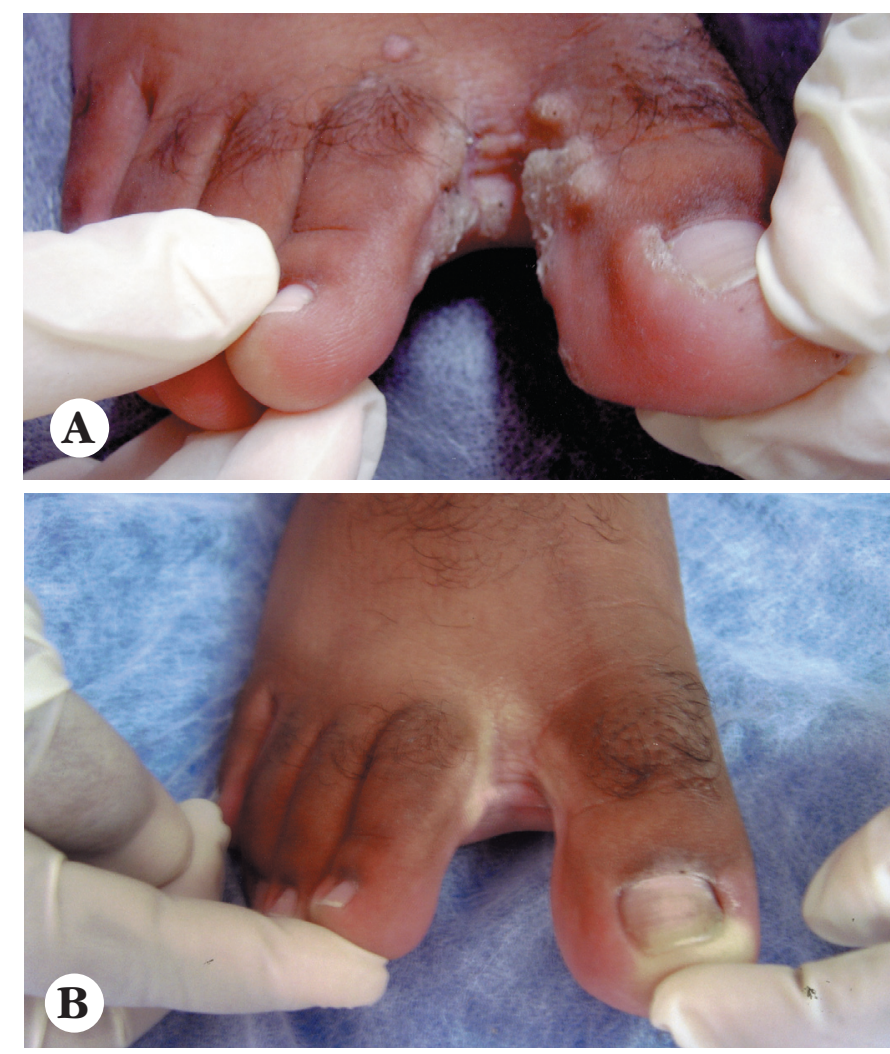

Figura 2: A: Paciente 2, com verrugas vulgares, periungueais e plantares antes de iniciar tratamento com sulfato de zinco; B: após terceiro mês de tratamento, com cura das lesões 
Mitsuishi e col. realizaram um trabalho com 55 pacientes de seis a 77 anos com verrugas múltiplas tratados com cimetidina por quatro meses. Os pacientes foram divididos em dois grupos, um recebendo $\leq 20 \mathrm{mg} / \mathrm{kg} / \mathrm{dia}$, e outro 30 a $40 \mathrm{mg} / \mathrm{kg} / \mathrm{dia}$, e foram medidos os níveis de interleucina 2 (IL-2), interleucina 18 (IL-18) e interferon gama (IFN- $\gamma$ ) de biópsias das lesões antes e durante o tratamento. Remissão completa ou melhora clínica dramática ocorreu em 34,5\%, e resposta parcial em $23,6 \%$. A remissão completa não dependeu do número de verrugas. Níveis de IL-2 e IFN- $\gamma$ aumentaram significativamente, e os de IL-18 diminuíram nas verrugas tratadas efetivamente, e os autores observaram também que doses mais altas de cimetidina são mais efetivas no tratamento de verrugas múltiplas. ${ }^{24}$

Orlow e Paller realizaram um trabalho com 32 crianças com verrugas múltiplas tratadas com cimetidina 25 a 40mg/kg/dia por dois meses, sendo que dois terços receberam juntamente tratamento tópico com preparações de ácido salicílico. Os resultados obtidos foram de $81 \%$ de cura, não tendo bons resultados para condiloma acuminado. ${ }^{8}$ Essa foi uma das melhores respostas relatadas na literatura com o uso da cimetidina para tratamento de verrugas múltiplas, não sendo observados tão bons resultados em outros trabalhos. Houve questionamento por outros autores pelo uso concomitante de tratamento tópico. ${ }^{21}$

Um estudo randomizado duplo-cego utilizando cimetidina em um grupo de crianças com verrugas recalcitrantes e cimetidina com levamisol em outro evidenciou cura completa das lesões em 31,5\% e 65\% respectivamente. ${ }^{25}$

Aos cinco pacientes do presente estudo que não responderam ao tratamento com cimetidina foi oferecido sulfato de zinco, sendo que apenas dois retornaram para as revisões, um apresentou cura após 30 dias de uso, e o outro não obteve resposta em dois meses de tratamento.

\section{CONCLUSÕES}

O sulfato de zinco na dose de $10 \mathrm{mg} / \mathrm{kg} /$ dia parece ser mais efetivo do que a cimetidina para o tratamento de crianças e adultos com verrugas múltiplas e recalcitrantes. A pequena casuística deste trabalho não permite uma conclusão categórica.

O uso da cimetidina não levou à cura de nenhum paciente, com resultados pouco expressivos, apenas com redução do tamanho em alguns casos e desaparecimento de poucas lesões.

\section{AGRADECIMENTOS}

A Fernanda Chalabi e à Farmácia de Manipulação Officilab, que forneceram gratuitamente os medicamentos necessários para a realização deste trabalho. 


\section{REFERÊNCIAS}

1. Sterling JC. Virus Infections. In: Burns T, Breathnach S, Cox $\mathrm{N}$ et al. Textbook of Dermatology. 7 ed. Oxford: Blackwell Science; 2004. p.25.37-53.

2. Vivier A. Atlas de Dermatologia Clínica. 2 ed. São Paulo: Editora Manole; 2000. p.12.10-4.

3. Azulay RD \& Azulay DR. Dermatologia. 5 ed. Rio de Janeiro: Guanabara Koogan; 2008. p.274-82.

4. Sampaio SAP, Rivitti EA. Dermatologia. 2 ed. São Paulo: Artes Médicas; 2000. p.418; 711.

5. Lowy DR, Androphy EJ. Verrugas. In: Freedberg IM, Eisen AZ, Wolff K, Austen KF, Goldsmith LA, Katz SI, et al. Fitzpatrick's dermatology in general medicine. 5 ed. Rio de Janeiro: Revinter; 2005. p.2484-95.

6. Al- Gurairi FT, Al- Waiz M, Sharquie KE. Oral zinc sulphate in the treatment of recalcitrant viral warts: randomized placebo- controlled clinical trial. $\mathrm{Br} \mathrm{J}$ Dermatol. 2002;146:423-31.

7. Stéphan F, Revuz J. Sels de zinc em dermatologie. Ann Dermatol Venerol. 2004;131:455-60.

8. Orlow SJ, Paller A. Cimetidine therapy for multiple warts in children. J Am Acad Dermatol.1993;28:794-6.

9. Choi YS, Hann SK, Park YK. The effect of cimetidine on verruca plana juvenilis: clinical trials in six patients. J Dermatol. 1993;20:487-500.

10. Brunton LL. Fármacos para controle da acidez gástrica e tratamento de úlceras pépticas. In: Goodman LS, Gilman A. As bases farmacológicas da terapêutica. 9 ed. Rio de Janeiro: McGraw-Hill; 1996.p.663-7.

11. Yielmaz E, Alpsoy E, Basaran E. Cimetidine therapy for warts: a placebo controlled double-blind study. J Am Acad Dermatol. 1996;34:1005-7.

12. Glass AT, Solomon BA. Cimetidine therapy for recalcitrant warts in adults. Arch Dermatol. 1996;132:680-2.

13. Fraker PJ, Jardieu P, Cook J. Zinc deficiency and immune function. Arch Dermatol. 1987;123:1699-701.

14. Couvreur Y, Quarre JP, Bailly A, Cornut P. Zinc deficiency and lymphocyte subpopulations, a study by flow cytometry. JPEN J Parenter Enteral Nutr. 1986;10:239-41.

15. Neldner KH. Acrodermatite enteropática e uutras afecções por deficiência de zinco. In: Freedberg IM, Eisen AZ, Wolff K, Austen KF, Goldsmith LA, Katz SI, et al. Fitzpatrick's dermatology in general medicine. 5 ed. Rio de Janeiro: Revinter; 2005.p.1738-43.
16. Arlette JP. Zinc deficiency in children. Int J Dermatol. 1982;21:447-8.

17. Scheinfeld N. Cimetidine: a review of the recent developments and reports in cutaneous medicine. Dermatol Online J. 2003;9:1-4.

18. Micali G, Nasca MR, Dall'Oglio F, Musumeci ML. Cimetidine therapy for epidermodysplasia verruciformis. J Am Acad Dermatol. 2003;48(Suppl 2):S9-10.

19. Paller AS. Cimetidine for the treatment of warts. West J Med.1996;164:520-1.

20. Gooptu C, Higgins CR, James MP. Treatment of viral warts with cimetidine: an open-label study. Clin Exp Dermatol. 2000;25:183-5.

21. Bauman C, Francis JS, Vanderhooft S, Sybert VP. Cimetidine therapy for multiple viral warts in children. J Am Acad Dermatol. 1996;35:271-2.

22. Rogers CJ, Gibney MD, Siegfried EC, Harrison BR, Glaser DA. Cimetidine therapy for recalcitrant warts in adults: is it any better than placebo? J Am Acad Dermatol. 1999; $41: 123-7$.

23. Karabulut AA, Sahin S, Eksioglu M. Is Cimetidine effective for nongenital warts: a double-blind, placebo-controlled study. Arch Dermatol. 1997;133:533-4.

24. Mitsuishi T, Iida K, Kawana S. Cimetidine treatment for viral warts enhances IL-2 and IFN- $\gamma$ expression but not IL-8 expression in lesional skin. Eur J Dermatol. 2003;13:445-8.

25. Parsad D, Pandhi R, Juneja A, Negi KS. Cimetidine and levamisole versus cimetidine alone for recalcitrant warts in children. Pediatr Dermatol. 2001;18:349-52.

ENDEREÇO PARA CORRESPONDÊNCIA / MAILING ADDRESS:

Mariane Stefani

Rua: Garibaldi 565/102, Centro

95080190 Caxias do Sul - RS

Tel./fax: (54) 32144277

E-mail: stefanimariane@ig.com.br

Como citar este artigo/How to cite this article: Stefani M, Bottino G, Fontenelle E, Azulay DR. Comparação entre a eficácia da cimetidina e do sulfato de zinco no tratamento de verrugas múltiplas e recalcitrantes. An Bras Dermatol. 2009;84(1):23-29. 